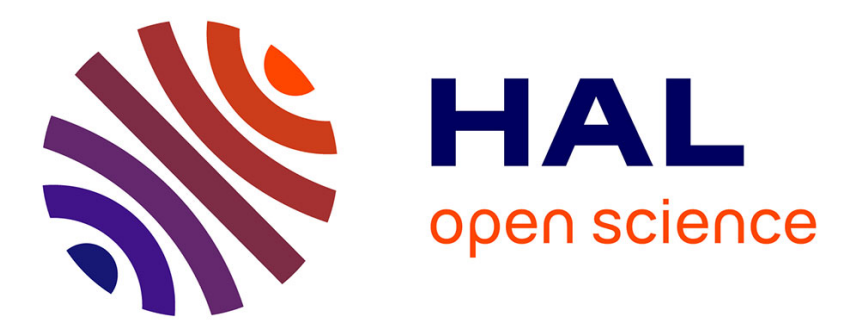

\title{
Immunochemical and molecular assessment of urothelial neoplasms and aspects of the 2016 WHO classification
}

\author{
Eva Compérat, Justine Varinot
}

\section{To cite this version:}

Eva Compérat, Justine Varinot. Immunochemical and molecular assessment of urothelial neoplasms and aspects of the 2016 WHO classification. Histopathology, 2016, 10.1111/his.13025 . hal-01379010

\section{HAL Id: hal-01379010 \\ https://hal.sorbonne-universite.fr/hal-01379010}

Submitted on 11 Oct 2016

HAL is a multi-disciplinary open access archive for the deposit and dissemination of scientific research documents, whether they are published or not. The documents may come from teaching and research institutions in France or abroad, or from public or private research centers.
L'archive ouverte pluridisciplinaire HAL, est destinée au dépôt et à la diffusion de documents scientifiques de niveau recherche, publiés ou non, émanant des établissements d'enseignement et de recherche français ou étrangers, des laboratoires publics ou privés. 
Immunochemical and molecular assessment of urothelial neoplasms and aspects of the 2016 WHO classification

New concepts in bladder cancer

Eva Compérat ${ }^{1}$ and Justine Varinot ${ }^{1}$

1. Department of Pathology, Hôpital Tenon, Paris, France, Université Pierre et Marie Curie - Paris 6, Paris, France

Corresponding author:

Dr Eva Compérat

Department of Pathology

Hôpital Tenon

4, Rue de la Chine

75020 Paris

Email: eva.omperat@aphp.fr

Tel: +33 142177788

Fax: +331421777 77

Authors have no conflict of interest to declare.

Word count: 3659 


\section{Abstract}

The new WHO classification 2016 of "4th edition of the WHO classification of Tumours of the Urinary System and Male Genital Organs" has several changes from previous versions and was published in January 2016. New pathways have been discovered in the development of bladder cancer and were included in this new classification. Guidance from the International Collaboration on Cancer Reporting (ICCR) helped clarify open questions in conjunction with the new classification. The histological groups of urothelial carcinoma (UC) evolved. Grading remained the same despite controversy among European urologists. Substaging pT1 tumours is recommended for the first time, and the ICCR has made recommendations on how to report this. Furthermore, worldwide advice has been published on the use of immunohistochemistry and recommendations try to standardise the handling of bladder cancer from a histopathological point of view. On a molecular level, bladder cancer groups have been stratified, and an upcoming molecular classification permits a novel view of this malignancy. This review will try to summarise the most important changes.

Keywords: bladder cancer; molecular classification; immunohistochemistry; WHO classification 
The new WHO classification "Tumours of the Urinary System and Male Genital Organs" was published in January 2016, 12 years after the previous. ${ }^{1}$ Several changes and major steps forward have been made and were included in this new classification. The histological concepts of urothelial carcinoma (UC) have evolved, substaging of pT1 tumours is now recommended, and breaking news has been made on a molecular level, permitting a novel view of bladder cancer. This review will try to summarise the most important changes.

Currently, histology is still the gold standard of UC diagnosis. The new WHO classification divides UC into two groups: non-invasive UC and infiltrating UC. The distinction of low-grade and high-grade lesions still exists and G1-3 should no longer be used. Although this grading system is used worldwide in the pathology community, several European urologists still employ the 1973 WHO grading system. The major problem is due to the European Association of Urology (EAU) guidelines, in which the voice of the pathologist is not heard by everybody although the lowgrade/high-grade system is partially included.

The new classification also underlines the clear interest in recognising variant histology as a predictor of more aggressive tumour behaviour. Some variants are known to be highly aggressive, such as plasmacytoid, micropapillary, sarcomatoid, and poorly differentiated UC, but some entities are still under-recognised and underdiagnosed. Reporting these entities is of major interest in regard to treatment and molecular classification, as some of these subtypes will not respond to cisplatinbased chemotherapies. ${ }^{2,3}$

\section{Histological subtypes}


From a purely histological and morphological point of view, some important changes have been made in subtype classification. Nested UC is the first entity of concern. In 2011, Cox et al. described a new group of large nested UC that presents the same problem as classical nested carcinomas. ${ }^{4}$ Histologically, they exhibit important exophytic growth and very few atypia, especially in the upper layers. In the deeper layers, the large nests are well delimited and the confirmation of invasion can be problematic. This group has to be distinguished from the inverted patterns and often exhibits detrusor muscle invasion in association with a more or less important stroma reaction, infiltrating nest feature, and few cytologic atypia, even when invading the muscle. It is important to report detrusor muscle invasion and recognise this growth pattern for appropriate treatment (Fig. 1A, B).

The lymphoma-like variant listed in the 2004 WHO classification has been added to the plasmacytoid/signet ring cell/diffuse UC group. Plasmacytoid UC is associated with classical high grade UC in $>50 \%$ cases". The signet ring cell variant was listed in the glandular neoplasm group in 2004 , but the concept has changed and this entity is no longer considered a glandular neoplasm. Generally, no extracellular mucin is observed and the variant has a striking resemblance to plasmacytoid UC. All of these carcinomas have diffuse growth patterns, often positive surgical margins, high stage, and poor outcome..$^{1,2,5}$

Another variant, clear cell UC, has also been introduced in the UC group. These UCs are also called glycogen-rich and exhibit cellular clarity, resembling clear cell carcinomas of the kidney. The growth pattern is mostly invasive, and an association with carcinoma in situ (CIS), papillary components, or more classical aspects of UC is common. Only a few cases have been described, making the outcome unclear, though some data seem to indicate aggressive behaviour (Fig. 2). ${ }^{6}$ 
Another newly introduced entity is the lipid-rich variant, characterised by large lipoblast-like cells. The lipid component normally accounts for $10-15 \%$ of the surface, and other more classical aspects of UC are seen (Fig. 3). Their behaviour also seems to be aggressive. ${ }^{7}$

The undifferentiated UC group in the 2004 classification has been renamed "poorly differentiated".

Two entities listed separately in the former classification but not indicated as wellseparated entities have been summarised in the "tumours of the Müllerian type" group. In the 2004 WHO classification, clear cell adenocarcinoma was considered a distinct variant of UC that resembles the Müllerian counterpart in the female genital tract. Now it is listed in the same group as endometroid tumours, both summarised under "tumours of the Müllerian type". However, the 2016 WHO classification is a little bit ambiguous on this point, as these tumours represent a specific form of glandular differentiation in UC. New data on outcomes have been published that demonstrate that low stage $(\mathrm{pT} 1 / 2)$ clear cell carcinomas with exophytic growth have better outcomes if treated aggressively. ${ }^{8}$

Another new section is urachal carcinoma. This entity is well known but has not previously been summarised in a distinct chapter. A separate staging system should be employed according to Sheldon (Table 1). ${ }^{9}$ Furthermore, four diagnostic criteria have been added in the new WHO classification ${ }^{10}$ : location of the tumour in the bladder dome and/or anterior wall, epicentre of UC in the bladder wall, absence of widespread cystitis cystica or cystitis glandularis beyond the dome or anterior wall, and absence of a known primary elsewhere. The most frequent subtype is non-cystic adenocarcinoma, which occurs in more than $80 \%$ of cases. ${ }^{10}$ 
In the non-UC groups, several important changes have to be noted. A new subgroup has been added to the neuroendocrine entity. No large cell neuroendocrine carcinomas were listed in the 2004 classification, but this very rare entity has been integrated in the 2016 classification. Like their small cell counterpart, prognosis is poor. ${ }^{11}$

Melanosis has been added as a new chapter for the melanocytic tumours. This aspect is normally benign, but some authors recommend follow-up because the finding is extremely rare. ${ }^{12}$

Inflammatory myofibroblastic tumour (IMT) of the bladder and perivascular epithelioid cell (PEC) tumours (benign and malignant variants) have also been added to the new classification. The first recurs frequently but rarely metastasises, whereas few malignant PEC tumours have been reported in the bladder and one case with metastasis has been described. ${ }^{13}$

New chapters have been added for the group of miscellaneous tumours with "epithelial tumours of the upper urinary tract", "tumours arising in a bladder diverticulum", and "urothelial tumours of the urethra".

\section{Substaging of pT1 tumours}

For the first time, the WHO classification also comments on the substaging of $\mathrm{T} 1$ tumours and considers it clinically relevant, but no agreement exists on which method should be employed. However, this change is a very important step forward. The previous classification did not recommend any substaging, though many papers demonstrated an important impact on patient outcomes. The clinical behaviour of pT1 tumours is highly variable, and there is an urgent need for more detailed risk stratification, which may include histological subtyping and substaging. Another 
prognostic factor is the grade of the lesion, and multifocality, tumour size, and concomitant CIS.

There are multiple reasons why substaging was not recommended for a long time. First, a major problem has always been the accuracy of the distinction between pTa and pT1 UC. As outlined by Lopez-Beltran and Cheng, a challenge in bladder pathology is the recognition of early invasion (stage pT1), and reproducibility between pathologists is a major issue. ${ }^{14}$ Pathology review results in considerable downstaging of pT1 to pTa in $28 \%$ to $55 \%$ of cases. ${ }^{15,16}$ Assessing invasion of the lamina propria may be very difficult, or even impossible in the case of superficial tumour sampling. Severe cautery and crush effects related to the urological procedure are also problematic. A recent paper tried to identify the contentious areas of invasion by asking eight established urogenital pathologists to annotate invasive areas on virtual slides from 25 cases initially considered to be pT1 tumours. Full agreement was achieved in only 11 cases (44\%). ${ }^{17}$ The most commonly encountered problems were the presence of smaller regular or irregular nests of tumour cells in close association with the sub-urothelial capillary network and individual rounded and well-demarcated nests of tumour cells in the stroma of the lamina propria, or cells that seemed to drop-off from these larger nests (Fig. 4).

Another reason for not recommending substaging in earlier classifications was the lack of consensus on how to proceed and which method to employ. Many authors have attempted to develop a substaging system for pT1 bladder cancers, but its general applicability may be limited because of poor orientation and fragmentation of the transurethral resection of the bladder. Also, evaluation of the extent into the lamina propria may be difficult. 
pT1 tumours include a wide range of invasive tumour volumes; they may consist of just a few scattered individual infiltrating cells or confluent tumour areas that destroy the underlying architecture. In the early 1990s, Younes was the first to propose the concept of substaging for pT1 tumours. ${ }^{18}$

The presence of muscularis mucosae $(\mathrm{MM})$ was described in 1983 by Dixon. ${ }^{19}$ Although a substaging system using MM as a landmark may seem relatively easy and user friendly, it also has its limits, as the MM may not be present in the bladder biopsy/resection specimen at the site of the invasive carcinoma. Herr et al. reported MM was missing in $40 \%$ of bladder resections and Bertz et al. reported this missing $17.5 \%$ of cases. $^{16,20}$ A two-tiered substaging system was proposed, with pT1a tumours defined as tumours without invasion beyond the MM and $\mathrm{pT} 1 \mathrm{~b}$ as those with invasion within and beyond the MM. Roupret et al. examined 587 bladder cancers in a multicentre study with central pathological review; $66 \%$ were pT1a tumours and the depth of infiltration could not be determined in $4 \%$. In a multivariate analysis, pT1b tumour stage was significantly associated with recurrence-free $(p=0.03)$, progressionfree $(p=0.0002)$, and cancer-specific $(p=0.02)$ survival. The authors considered MM invasion to be highly predictive of tumour behaviour. ${ }^{21}$

Cheng et al. found that the depth of invasion measured with an oculometer was a significant predictor of the final pathological stage at cystectomy. Tumours with an invasion depth $\geq 1.5 \mathrm{~mm}$ had a significantly higher probability of being advanced stage in cystectomies, the 5-year progression-free survival was $67 \%$ with a depth of invasion $>1.5 \mathrm{~mm}$ and $93 \%$ with a depth of invasion $\leq 1.5 \mathrm{~mm} .^{22}$ Van der Aa distinguished pT1foc with microinvasive features, defined as a single focus of invasion of the subepithelial stroma by an invasive front parallel to the overlying neoplastic urothelium over a maximum distance of $0.5 \mathrm{~mm}$ (i.e., within one high 
power (x40) field, HPF). Extensive infiltration could be single or multifocal microinvasive areas not fitting within one HPF. The diagnostic reproducibility is $81 \%$, and extensive infiltration is the strongest predictor of progression. ${ }^{23}$ More recently, Chang et al. compared three cut-off values for substaging purposes: $\leq 0.5 \mathrm{~mm}$ for high-grade pT1 tumours, up to $1 \mathrm{~mm}$ for focal invasion, and $1.5 \mathrm{~mm}$ for extensive invasion. The authors found comparable statistical results with 0.5 and $1.5 \mathrm{~mm}$ cutoffs, recommending $1 \mathrm{~mm}$ for practical reasons. They underlined the feasibility of this methodology in TURBs in order to identify patients with less favourable outcomes. ${ }^{24}$

The International Collaboration on Cancer Reporting (ICCR), an international working group, recently published recommendations on minimal items in reports of bladder tumour. They suggest using either depth of invasion or total maximum dimension of the invasive tumour or $\mathrm{pT} 1 \mathrm{a} / \mathrm{b}$ (invasion above or beyond the MM) ${ }^{25}$

\section{Immunohistochemical assessment}

Several recent papers explored the immunoreactivity of different bladder cancer subtypes. Paner et al. recently compared the most frequent UC types, ${ }^{26}$ underlining the usefulness of several immunomarkers, including GATA-3, S-100P, CK7, CK20, HMCK, and p63, to confirm the usefulness of urothelial origin (Table 2).

Mohanty et al. also recently tested poorly differentiated bladder neck resections. The immunohistochemical results were the same for tumours of urothelial origin. They also explored carcinomas of prostatic origin using a panel of prostate cancer markers (Table 3). ${ }^{27}$ This paper underlined Paner's results and indicated that PSA underperforms compared to novel prostate-specific markers, except for androgen receptor, which was positive in $13 \%$ of UCs. 
In 2014, recommendations concerning the application of immunohistochemistry in the bladder were published after the ISUP meeting in $2013 .^{28}$ The committee considered that there was no ideal marker to confirm urothelial differentiation. GATA-3, CK20, p63, HMWCK, or CK5/6 is valuable if the clinical context and morphology indicate urothelial origin. In the dysplasia and CIS group, morphology is still the gold standard, and the immunohistochemistry panel should be CK20/p53 and CD44. However, it is important for the pathologist to be aware of the limitations. If no clear cut-offs have been provided for interpreting the immunohistochemistry of CIS, CK20 should be expressed in the entire thickness of the urothelium, CD44 absent in atypical cells, and atypical cells intensely positive for p53. Many pathologists also use Ki-67, which is a well-known marker in $\mathrm{CIS}^{29}$

A tricky topic is spindle cell lesions in the bladder. Several groups have to be distinguished: pseudosarcomatous myofibroblastic proliferation (PMP), IMT, sarcomatoid UC, leiomyosarcoma (LMS), and rhabdomyosarcoma (RMS). The following results (Table 3) should be obtained with immunohistochemistry, though it is obvious that immunohistological criteria will not allow a diagnosis of spindle cell lesion. Morphology is the most important criterion, but will not be discussed in this review. The ISUP recommends a panel of six antibodies, RMS is mostly not a major problem, as age, clinical history, and nuclear MyoD1 will confirm the diagnosis (Table $4)$.

Last but not least, there is the remaining question of prognostic immunomarkers. Many have been described in the literature, but no immunohistochemical marker is recommended for routine performance on biopsies or resections. ${ }^{28}$

\section{Familial UC}


Until now, UC has been considered an exposure-related disease, but several papers have reported a genetic disposition in rare cases. Hereditary susceptibility disorders also exist in the bladder. For the upper urinary tract, the predisposition for UC is well established with Lynch syndrome, it was recently shown that few of these patients can also develop UC in the bladder. $^{30}$ Genome-wide association studies have identified several independent genomic regions associated with bladder cancer risk. Figuero et al. recently described two susceptibility loci, one in the 13q34 region and a second in the 20p12.2 region, that seem to be strongly associated with the risk of muscle-invasive (T2-T4 stage) UC, as opposed to non-muscle-invasive (Ta, T1 stage) UC. ${ }^{31}$ On the other hand, tumours in patients over 20 years of age are not significantly different from those in patients of an older age..$^{30}$

\section{Genetic changes}

The most important criterion for optimal cancer treatment is accurate classification of the tumour. During the last 3 years, important progress has been made with a better definition of UC, especially from a molecular point of view. We have started to gain a global understanding of UC, though many details are still not completely understood.

One of the major problems with UC is the extremely heterogeneous genetic profile. Major familial syndromes are missing, and UC is extremely exposure-dependent. Genetic evidence indicates at least two major pathways: one from urothelial proliferation of uncertain malignant potential (previously called hyperplasia) towards low-grade non-invasive papillary UC, and the other from dysplasia/atypia towards $\mathrm{CIS}$ and further to high-grade invasive UC. ${ }^{32} \mathrm{~A}$ marked genetic difference exists between low-grade and high-grade tumours, but many supplementary pathways interfere in the development of UC. 
UC can be monoclonal or polyclonal; therefore, multifocal or metachronous tumours can exhibit the same mutations, but also novel and different acquired mutations. ${ }^{33}$

Several different pathways have been described for the different genetic modifications in UC. Chromosomal alterations have been reported, some of them known already, such as $C D K N 2 A, R B 1$, and E2F3. The spectrum of mutations is large, and recurrent mutations have been described in, for example, TP53, FGFR3, and PIK3CA. The Cancer Genome Atlas revealed 302 mutations, 204 segmental copy number alterations, and on average 22 rearrangements per tumour. Recurrent driver mutations were found in 32 genes, including cell cycle regulation genes, kinase signalling pathways, and nine additional genes unknown to date. Compared to lung cancers and melanomas, UC has the most frequent mutation rate. ${ }^{34}$

The FGFR3/RAF/RAS pathway regulates several genes that are important for the cell cycle. One quite well-known fusion gene is FGFR3-TACC3, which activates FGFR3, a protein known to play a role in non-invasive low-grade tumours. Other pathways, such as the $\mathrm{PI} 3 \mathrm{~K} / \mathrm{AKT} / \mathrm{mT}$ tor pathway, which controls processes in carcinogenesis such as cell growth and proliferation, or Notch, which is an important actor in cell-cell communication, also play important roles in bladder cancer development. Until now, a not too well-known was the chromatin remodelling pathway. Changes in the chromatin structure lead to altered gene expression, but there seem to be many further and not entirely understood steps in bladder carcinogenesis. ${ }^{3,34}$

Recent studies have made very important steps forward in understanding UC. In particular, the group around Sjödahl has shown distinct UC groups. According to gene expression profiles, they could distinguish five UC groups: urobasal A, urobasal B, genomically unstable, infiltrated, and squamous cell carcinoma-like bladder 
cancers. Interestingly, these tumours exhibited different cytokeratin signatures and keratinisation-associated antigens. They also exhibit different mutations and FGFR3 gene expression signatures. Furthermore, distinct molecular subtypes have different cell adhesion gene signatures. The authors claimed that the tumour groups were completely pathology-independent, but when analysing the subgroups, some groups such as urobasal A contain a large amount of low-grade Ta and T1 tumours. The T1 group is described as a very heterogeneous group of tumours, which is particularly true when regarding the clinical behaviour of these carcinomas. ${ }^{35}$

In another recent paper the mRNA expression of progression biomarkers revealed a strong association with molecular subtype. The risk of progression was low for urobasal tumours and higher for genetically unstable and squamous cell carcinomalike bladder cancers. Risk factors for progression, such as multifocality, concomitant CIS, invasion depth, and lymphovascular invasion were seen globally only in the latter two groups. Therefore, the authors concluded that, in the T1 group, molecular substaging seems to be of major interest and helps identify patients with more aggressive disease. ${ }^{36}$

Choi et al. recently demonstrated separate tumour groups according to luminal and basal subtypes, a concept that has already been explored in breast and head and neck cancers. They demonstrated a link between histology and gene expression signatures. Basal tumours were enriched with sarcomatoid features and often had metastatic disease at presentation. These tumours also expressed high levels of epidermal growth factor receptor (EGFR) and several of its ligands. Another characteristic of the basal-type group was the expression of several cytokeratins, confirming the results of the Sjödahl group. These data were especially true for basal tumours that invaded the detrusor muscle. The luminal group was rich with epithelial 
biomarkers, such as E-cadherin, and exhibited high levels of FGFR3 mutations. An upregulation of the proliferator activator (PPAR) pathway, as well as oestrogen receptor (ER) and its co-activator Trim-24, was also reported. ${ }^{35}$

Choi et al. also described a subgroup of luminal tumours that they called "p53-like" luminal muscle invasive bladder cancers (MIBCs). This group could be distinguished from the luminal group by their expression of an active p53-associated gene expression signature. This expression was not associated with the presence of wildtype TP53. Interestingly, these UCs also contained an active p16 gene signature. This pathway is also known to play a major role in the development of aggressive UC. ${ }^{35}$

The aims of characterising groups and subgroups is to find possible and optimal drug targets. Histological classification, which is still the gold standard, helps aid in decision-making, such as BCG treatment or neoadjuvant chemotherapy and surgery.

The molecular classification could help progress towards refining chemotherapy in these patients. When defining subgroups of bladder cancer on a molecular level, we can avoid treating patients with chemoresistance. Neoadjuvant cisplatin-based chemotherapy is the current standard and recommended in the EAU guidelines for the treatment of patients with MIBC (Fig. 5). ${ }^{37}$

Choi et al. described chemoresistance for all p53-like luminal MIBCs, but the cohort only contained seven patients. They then extended the cohort and confirmed the first findings. They also demonstrated that luminal and basal types responded in more than $50 \%$ of neoadjuvant chemotherapy. ${ }^{38}$

Sjödahl et al. had a different approach to UC treatment. They compared possible drugs with drug target genes, showing that the gene expression of potential drug 
targets was associated with molecular subtypes. Pathological stratification seemed to play a minor role. ${ }^{35} \mathrm{~A}$ recent study by McConkey et al. enrolled 60 patients in a neoadjuvant trial of four cycles of dose dense methotrexate, vinblastine, doxorubicin, and cisplatin (MVAC) associated with bevacizumab. The patients underwent gene expression profiling before treatment in order to benefit from chemotherapy according to their "molecular" UC. Basal UC had improved survival compared to luminal and p53-like UC. In this study the p53-like luminal type also exhibited chemoresistance and more aggressive disease with bone metastasis. The authors concluded that there is a benefit to treating patients according to their genetic profile. In the sense of personalised medicine, it could be interesting to treat only chemosensitive patients. ${ }^{39}$ Apparently, in the very near future UC will not only be treated according to histological grading and staging, but molecular and genetic profiles will also play a major role. This will help select only chemosensitive patients, but also avoid heavy treatment of patients who will not benefit from chemotherapy. Nevertheless, histology will maintain an important place because it permits quick and low cost diagnosis. Ideally, both classifications should be employed in the future. 


\section{References}

1. 4th edition of the WHO classification of Tumours of the Urinary System and Male Genital Organs [Internet]. Enup. 2014 [cité 10 févr 2016]. Disponible sur: http://enup.org/4th-edition-classification-tumours-urinary-system-male-genitalorgans/

2. Keck B, Wach S, Stoehr R, Kunath F, Bertz S, Lehmann J, et al. Plasmacytoid variant of bladder cancer defines patients with poor prognosis if treated with cystectomy and adjuvant cisplatin-based chemotherapy. BMC Cancer. 2013;13:71.

3. Höglund M. On the origin of syn- and metachronous urothelial carcinomas. Eur Urol. mai 2007;51(5):1185-1193; discussion 1193.

4. Cox R, Epstein Jl. Large nested variant of urothelial carcinoma: 23 cases mimicking von Brunn nests and inverted growth pattern of noninvasive papillary urothelial carcinoma. Am J Surg Pathol. sept 2011;35(9):1337-42.

5. Dayyani F, Czerniak BA, Sircar K, Munsell MF, Millikan RE, Dinney CP, et al. Plasmacytoid urothelial carcinoma, a chemosensitive cancer with poor prognosis, and peritoneal carcinomatosis. J Urol. mai 2013;189(5):1656-61.

6. Oliva $E$, Amin MB, Jimenez $R$, Young $R H$. Clear cell carcinoma of the urinary bladder: a report and comparison of four tumours of mullerian origin and nine of probable urothelial origin with discussion of histogenesis and diagnostic problems. Am J Surg Pathol. févr 2002;26(2):190-7. 
7. Lopez-Beltran A, Amin MB, Oliveira PS, Montironi R, Algaba F, McKenney JK, et al. Urothelial carcinoma of the bladder, lipid cell variant: clinicopathologic findings and LOH analysis. Am J Surg Pathol. mars 2010;34(3):371-6.

8. Kurosaka S, Irie A, Mizoguchi H, Okuno N, Iwabuchi K, Baba S. Advanced clearcell adenocarcinoma of the bladder successfully treated by radical surgery with adjuvant chemoradiotherapy. Int J Clin Oncol. oct 2005;10(5):362-5.

9. Sheldon CA, Clayman RV, Gonzalez R, Williams RD, Fraley EE. Malignant urachal lesions. J Urol. janv 1984;131(1):1-8.

10. Gopalan A, Sharp DS, Fine SW, Tickoo SK, Herr HW, Reuter VE, et al. Urachal carcinoma: a clinicopathologic analysis of 24 cases with outcome correlation. Am J Surg Pathol. mai 2009;33(5):659-68.

11. Colarossi C, Pino P, Giuffrida D, Aiello E, Costanzo R, Martinetti D, et al. Large cell neuroendocrine carcinoma (LCNEC) of the urinary bladder: a case report. Diagn Pathol. 2013;8:19.

12. Patel P, Gotto G, Kavanagh A, Al Bashir S, Bismar TA, Trpkov K. Urinary bladder melanosis associated with urothelial dysplasia and invasive urothelial carcinoma: a report of two cases. Anal Quant Cytopathol Histopathol. oct 2013;35(5):294-300.

13. Williamson SR, Bunde PJ, Montironi R, Lopez-Beltran A, Zhang S, Wang M, et al. Malignant perivascular epithelioid cell neoplasm (PEComa) of the urinary bladder with TFE3 gene rearrangement: clinicopathologic, immunohistochemical, and molecular features. Am J Surg Pathol. oct 2013;37(10):1619-26. 
14. Lopez-Beltran A, Cheng L. Stage pT1 bladder carcinoma: diagnostic criteria, pitfalls and prognostic significance. Pathology (Phila). déc 2003;35(6):484-91.

15. Tosoni I, Wagner U, Sauter G, Egloff M, Knönagel H, Alund G, et al. Clinical significance of interobserver differences in the staging and grading of superficial bladder cancer. BJU Int. janv 2000;85(1):48-53.

16. Herr HW. The value of a second transurethral resection in evaluating patients with bladder tumours. J Urol. juill 1999;162(1):74-6.

17. Compérat E, Egevad L, Lopez-Beltran A, Camparo P, Algaba F, Amin M, et al. An interobserver reproducibility study on invasiveness of bladder cancer using virtual microscopy and heatmaps. Histopathology. déc 2013;63(6):756-66.

18. Younes M, Sussman J, True LD. The usefulness of the level of the muscularis mucosae in the staging of invasive transitional cell carcinoma of the urinary bladder. Cancer. 1 août 1990;66(3):543-8.

19. Dixon JS, Gosling JA. Histology and fine structure of the muscularis mucosae of the human urinary bladder. J Anat. mars 1983;136(Pt 2):265-71.

20. Bertz S, Denzinger S, Otto W, Wieland WF, Stoehr R, Hofstaedter F, et al. Substaging by estimating the size of invasive tumour can improve risk stratification in PT1 urothelial bladder cancer-evaluation of a large hospital-based single-centre series. Histopathology. oct 2011;59(4):722-32.

21. Rouprêt M, Seisen T, Compérat E, Larré S, Mazerolles C, Gobet F, et al. Prognostic interest in discriminating muscularis mucosa invasion (T1a vs T1b) in 
nonmuscle invasive bladder carcinoma: French national multicenter study with central pathology review. J Urol. juin 2013;189(6):2069-76.

22. Cheng L, Weaver AL, Neumann RM, Scherer BG, Bostwick DG. Substaging of T1 bladder carcinoma based on the depth of invasion as measured by micrometer: A new proposal. Cancer. 15 sept 1999;86(6):1035-43.

23. van der Aa MNM, van Leenders GJLH, Steyerberg EW, van Rhijn BW, Jöbsis AC, Zwarthoff EC, et al. A new system for substaging pT1 papillary bladder cancer: a prognostic evaluation. Hum Pathol. sept 2005;36(9):981-6.

24. Chang W-C, Chang $\mathrm{Y}-\mathrm{H}$, Pan $\mathrm{C}-\mathrm{C}$. Prognostic significance in substaging ofT1 urinary bladder urothelial carcinoma on transurethral resection. Am J Surg Pathol. mars 2012;36(3):454-61.

25. Datasets - International Collaboration on Cancer Reporting [Internet]. [cité 10 mai 2016]. Disponible sur: http://www.iccr-cancer.org/datasets

26. Paner GP, Annaiah C, Gulmann C, Rao P, Ro JY, Hansel DE, et al. Immunohistochemical evaluation of novel and traditional markers associated with urothelial differentiation in a spectrum of variants of urothelial carcinoma of the urinary bladder. Hum Pathol [Internet]. [cité 30 mai 2014]; Disponible sur: http://www.sciencedirect.com/science/article/pii/S0046817714001105

27. Mohanty SK, Smith SC, Chang E, Luthringer DJ, Gown AM, Aron M, et al. Evaluation of contemporary prostate and urothelial lineage biomarkers in a consecutive cohort of poorly differentiated bladder neck carcinomas. Am J Clin Pathol. août 2014;142(2):173-83. 
28. Amin MB, Smith SC, Reuter VE, Epstein JI, Grignon DJ, Hansel DE, et al. Update for the practicing pathologist: The International Consultation On Urologic Disease-European association of urology consultation on bladder cancer. Mod Pathol Off J U S Can Acad Pathol Inc. mai 2015;28(5):612-30.

29. Compérat E, Camparo P, Haus R, Chartier-Kastler E, Radenen B, Richard F, et al. Aurora-A/STK-15 is a predictive factor for recurrent behaviour in noninvasive bladder carcinoma: a study of 128 cases of non-invasive neoplasms. Virchows Arch Int J Pathol. avr 2007;450(4):419-24.

30. Owen HC, Giedl J, Wild PJ, Fine SW, Humphrey PA, Dehner LP, et al. Low frequency of epigenetic events in urothelial tumours in young patients. J Urol. août 2010;184(2):459-63.

31. Figueroa JD, Middlebrooks CD, Banday AR, Ye Y, Garcia-Closas M, Chatterjee $\mathrm{N}$, et al. Identification of a novel susceptibility locus at $13 q 34$ and refinement of the 20p12.2 region as a multi-signal locus associated with bladder cancer risk in individuals of European ancestry. Hum Mol Genet. 15 mars 2016;25(6):1203-14.

32. Majewski T, Lee S, Jeong J, Yoon D-S, Kram A, Kim M-S, et al. Understanding the development of human bladder cancer by using a whole-organ genomic mapping strategy. Lab Investig J Tech Methods Pathol. juill 2008;88(7):694-721.

33. Knowles MA, Hurst CD. Molecular biology of bladder cancer: new insights into pathogenesis and clinical diversity. Nat Rev Cancer. janv 2015;15(1):25-41. 
34. Cancer Genome Atlas Research Network. Comprehensive molecular characterization of urothelial bladder carcinoma. Nature. 20 mars 2014;507(7492):315-22.

35. Sjödahl G, Lauss M, Lövgren K, Chebil G, Gudjonsson S, Veerla S, et al. A molecular taxonomy for urothelial carcinoma. Clin Cancer Res Off $\mathrm{J}$ Am Assoc Cancer Res. 15 juin 2012;18(12):3377-86.

36. Patschan O, Sjödahl G, Chebil G, Lövgren K, Lauss M, Gudjonsson S, et al. A Molecular Pathologic Framework for Risk Stratification of Stage T1 Urothelial Carcinoma. Eur Urol. nov 2015;68(5):824-832-836.

37. Choi W, Porten S, Kim S, Willis D, Plimack ER, Hoffman-Censits J, et al. Identification of distinct basal and luminal subtypes of muscle-invasive bladder cancer with different sensitivities to frontline chemotherapy. Cancer Cell. 10 févr 2014;25(2):152-65.

38. Witjes JA, Compérat E, Cowan NC, De Santis M, Gakis G, Lebret T, et al. EAU guidelines on muscle-invasive and metastatic bladder cancer: summary of the 2013 guidelines. Eur Urol. avr 2014;65(4):778-92.

39. McConkey DJ, Choi W, Shen Y, Lee I-L, Porten S, Matin SF, et al. A Prognostic Gene Expression Signature in the Molecular Classification of Chemotherapy-naïve Urothelial Cancer is Predictive of Clinical Outcomes from Neoadjuvant Chemotherapy: A Phase 2 Trial of Dose-dense Methotrexate, Vinblastine, Doxorubicin, and Cisplatin with Bevacizumab in Urothelial Cancer. Eur Urol. 2 sept 2015. 
Tables

Table 1. The recommended Shelon system for staging urachal carcinomas.

\begin{tabular}{|l|l|}
\hline Stage & Definition \\
\hline I & $\begin{array}{l}\text { Carcinoma confined to the urachal } \\
\text { mucosa }\end{array}$ \\
\hline II & $\begin{array}{l}\text { Carcinoma invasion confined to the } \\
\text { urachus }\end{array}$ \\
\hline III & Local carcinoma extension \\
IIIA & Extension into the bladder \\
IIIC & Extension into the abdominal wall \\
\hline IV & Extension into the peritoneum \\
IVA & Metastasis \\
IVB & Metastasis to lymph nodes \\
\hline
\end{tabular}

Table 2. Immunoreactivity of different bladder cancer subtypes.

\begin{tabular}{|l|l|l|l|l|l|l|l|l|}
\hline & $\begin{array}{l}\text { GATA } \\
3\end{array}$ & $\begin{array}{l}\text { S- } \\
100 \mathrm{P}\end{array}$ & $\begin{array}{l}\text { UPII } \\
\text { I }\end{array}$ & $\begin{array}{l}\text { Thrombomodul } \\
\text { in }\end{array}$ & CK7 & $\begin{array}{l}\text { CK2 } \\
0\end{array}$ & p63 & $\begin{array}{l}\text { HMC } \\
\text { K }\end{array}$ \\
\hline $\begin{array}{l}\text { Conventional } \\
\text { UC }\end{array}$ & $80 \%$ & $80 \%$ & $50 \%$ & $50 \%$ & $70 \%$ & $44 \%$ & $\begin{array}{l}100 \\
\%\end{array}$ & $78 \%$ \\
\hline $\begin{array}{l}\text { UC with } \\
\text { squamous } \\
\text { differentiation }\end{array}$ & $20 \%$ & $78 \%$ & $0 \%$ & $70 \%$ & $80 \%$ & $20 \%$ & $\begin{array}{l}100 \\
\%\end{array}$ & $100 \%$ \\
\hline $\begin{array}{l}\text { UC with } \\
\text { glandular } \\
\text { differentiation }\end{array}$ & $50 \%$ & 100 & $10 \%$ & $0 \%$ & $90 \%$ & $\begin{array}{l}100 \\
\%\end{array}$ & $60 \%$ & $90 \%$ \\
\hline Micropapillary & $86 \%$ & $96 \%$ & $38 \%$ & $38 \%$ & $\begin{array}{l}100 \\
\%\end{array}$ & $73 \%$ & $54 \%$ & $96 \%$ \\
\hline Plasmacytoid & $100 \%$ & 100 & $8 \%$ & $45 \%$ & $70 \%$ & $60 \%$ & $50 \%$ & $90 \%$ \\
\hline Nested & $70 \%$ & $90 \%$ & $40 \%$ & $55 \%$ & $\begin{array}{l}100 \\
\%\end{array}$ & $30 \%$ & $\begin{array}{l}100 \\
\%\end{array}$ & $100 \%$ \\
\hline Clear cell & $100 \%$ & 100 & $66 \%$ & $100 \%$ & $\begin{array}{l}100 \\
\%\end{array}$ & $100 \%$ \\
\hline Microcystic & $100 \%$ & $\begin{array}{l}100 \\
\%\end{array}$ & $50 \%$ & $25 \%$ & $50 \%$ & $\begin{array}{l}100 \\
\%\end{array}$ & $100 \%$ \\
\hline Undifferentiate & $30 \%$ & $70 \%$ & $0 \%$ & $20 \%$ & $70 \%$ & $0 \%$ & $70 \%$ & $80 \%$ \\
\hline
\end{tabular}




\begin{tabular}{|l|l|l|l|l|l|l|l|l|}
\hline $\mathrm{d}$ & & & & & & & & \\
\hline $\begin{array}{l}\text { Small cell } \\
\text { carcinoma }\end{array}$ & $25 \%$ & $0 \%$ & $0 \%$ & $10 \%$ & $25 \%$ & $0 \%$ & $8 \%$ & $9 \%$ \\
\hline $\begin{array}{l}\text { Sarcomatoid } \\
\text { carcinoma }\end{array}$ & $20 \%$ & $27 \%$ & $0 \%$ & $31 \%$ & $56 \%$ & $6 \%$ & $69 \%$ & $56 \%$ \\
\hline
\end{tabular}

UC, urothelial carcinoma.

Table 3. Prostatic marker expression in prostate cancer and urothelial carcinoma (UC).

\begin{tabular}{|l|l|l|l|l|l|l|}
\hline & PSA & P501s & NKX3.1 & PSMA & $\begin{array}{l}\text { Androgen } \\
\text { receptor }\end{array}$ & ERG \\
\hline Prostate & 75 & 100 & 100 & 100 & 100 & 35 \\
\hline UC & 0 & 0 & 0 & 0 & 13 & 0 \\
\hline
\end{tabular}

Table 4. Spindle cell lesions and expected immunoprofiles.

\begin{tabular}{|c|c|c|c|}
\hline Entity & Expected Immunopr & file & \\
\hline & + & $+/-$ & - \\
\hline Sarcomatoid UC & AE1/AE3 & $\begin{array}{l}\text { p63, HMWCK, } \\
\text { CK5/6, SMA }\end{array}$ & desmin, AKL1 \\
\hline PMP/IMT & AE1/AE3, SMA & desmin, AKL1 & $\begin{array}{ll}\text { p63, } & \text { HMWCK, } \\
\text { CK5/6 } & \end{array}$ \\
\hline LMS & desmin, SMA & $\begin{array}{ll}\text { p63, } & \text { HMWCK, } \\
\text { CK5/6 }\end{array}$ & AE1/AE3 -, ALK1 \\
\hline RMS & $\begin{array}{l}\text { desmin, SMA, } \\
\text { myogenin, myoD1 }\end{array}$ & ALK1 & $\begin{array}{l}\text { keratin, p63, } \\
\text { HMWCK, CK5/6 }\end{array}$ \\
\hline
\end{tabular}

IMT, inflammatory myofibroblastic tumour; LMS, leiomyosarcoma; PMP, pseudosarcomatous myofibroblastic proliferation; RMS, rhabdomyosarcoma; UC, urothelial carcinoma. 


\section{Figure legends}

Figure 1. Hematoxylin and eosin staining of a large nested urothelial carcinoma (UC). (A) The tumour invaded the detrusor muscle, 1.25x magnification. (B) No cytological atypia in the nests invading the bladder wall, 20x magnification.

Figure 2. Clear cell urothelial carcinoma. The cells mimic clear cell kidney cancer. Hematoxylin and eosin stain, 20x magnification.

Figure 3. Lipid-rich urothelial carcinoma associated with a more classical aspect.

Figure 4. Small regular nests and drop-off cells. Hematoxylin and eosin stain, 4x magnification.

Figure 5. Different histological subtypes according to the molecular classification. (A) Classical urothelial carcinoma (UC). (B) Patchy and weak focal CK5/6 staining. (C) Strong and cytoplasmic/membranous CK7 staining. (D) Homogenous nuclear GATA-

3 staining. (E) Squamous differentiation of UC. (F) Strong CK5/6-positivity. (G) No CK7 expression in tumour cells. $(\mathrm{H})$ Absence of GATA-3 staining. 


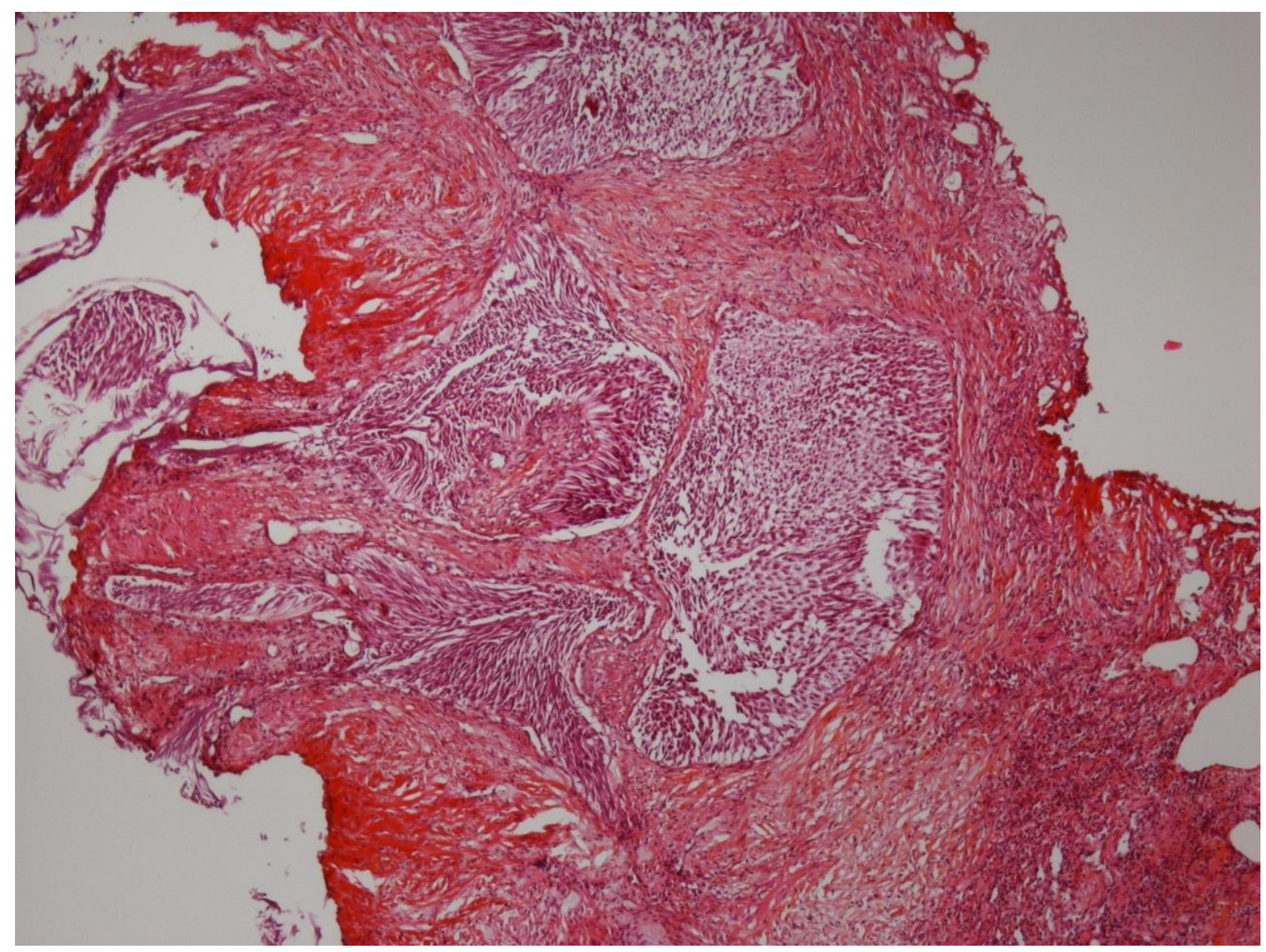

Fig. $1 \mathrm{~A}$ 


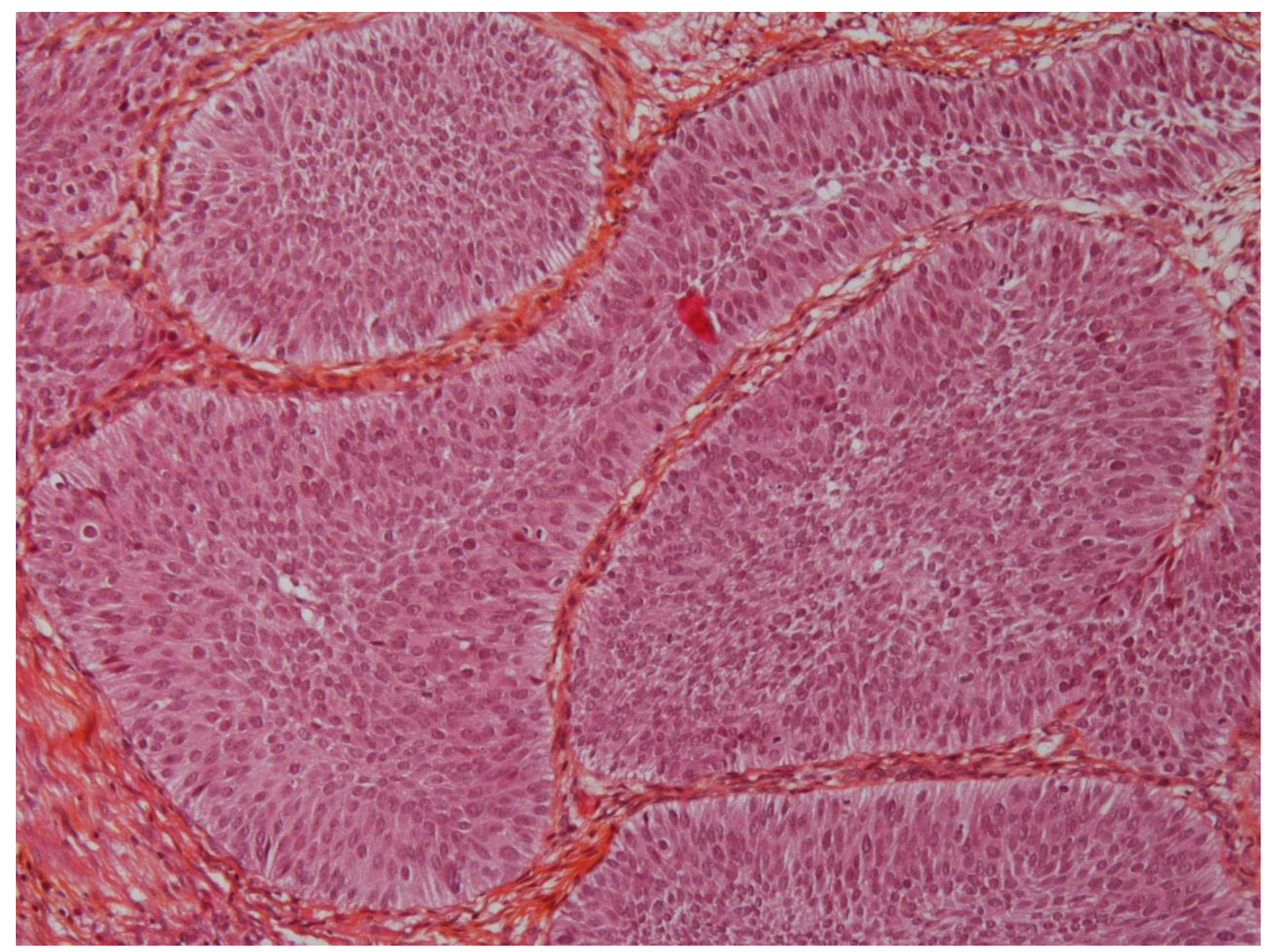

Fig. $1 \mathrm{~B}$ 


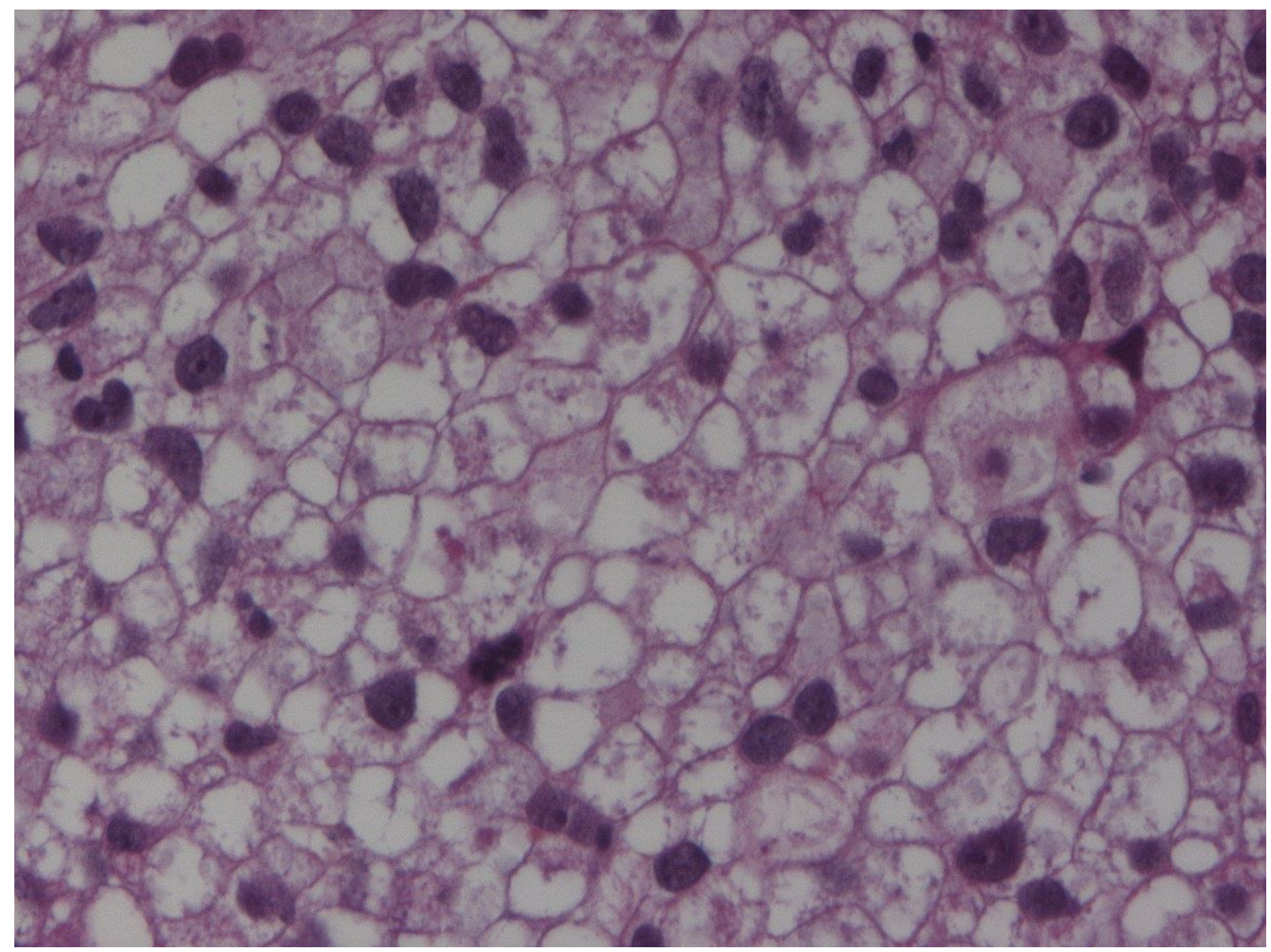

Fig. 2 


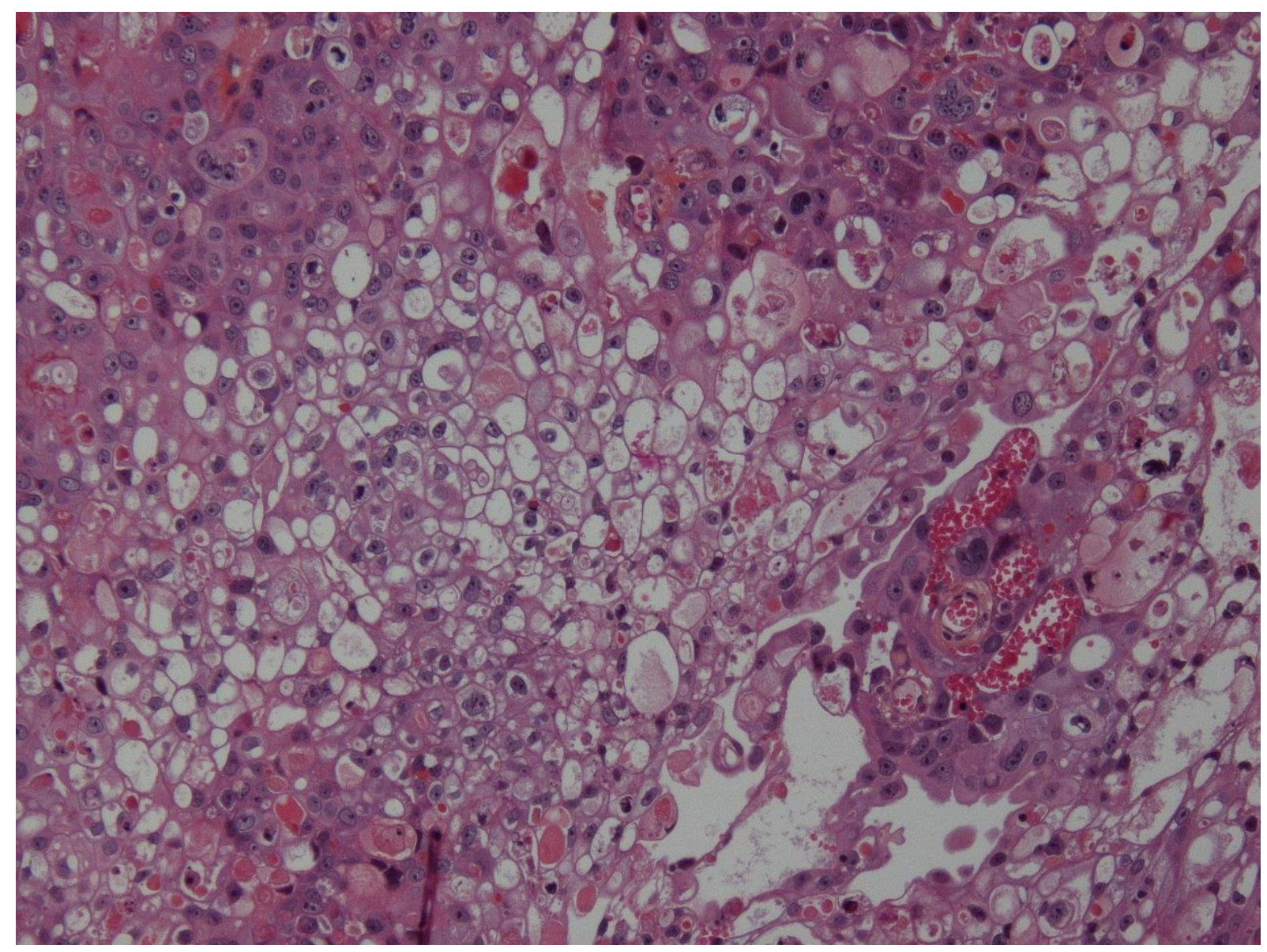

Fig. 3 


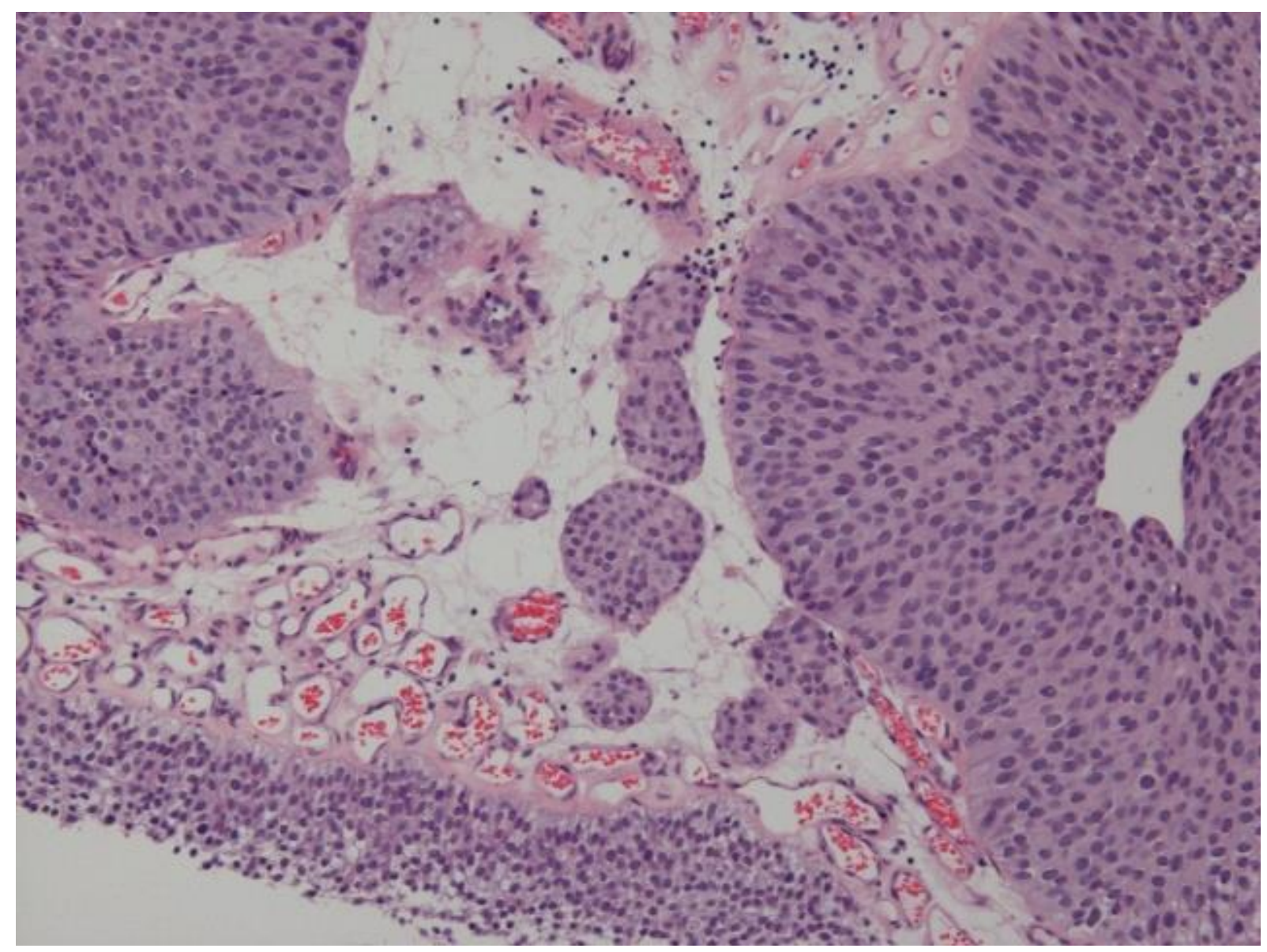

Fig. 4 


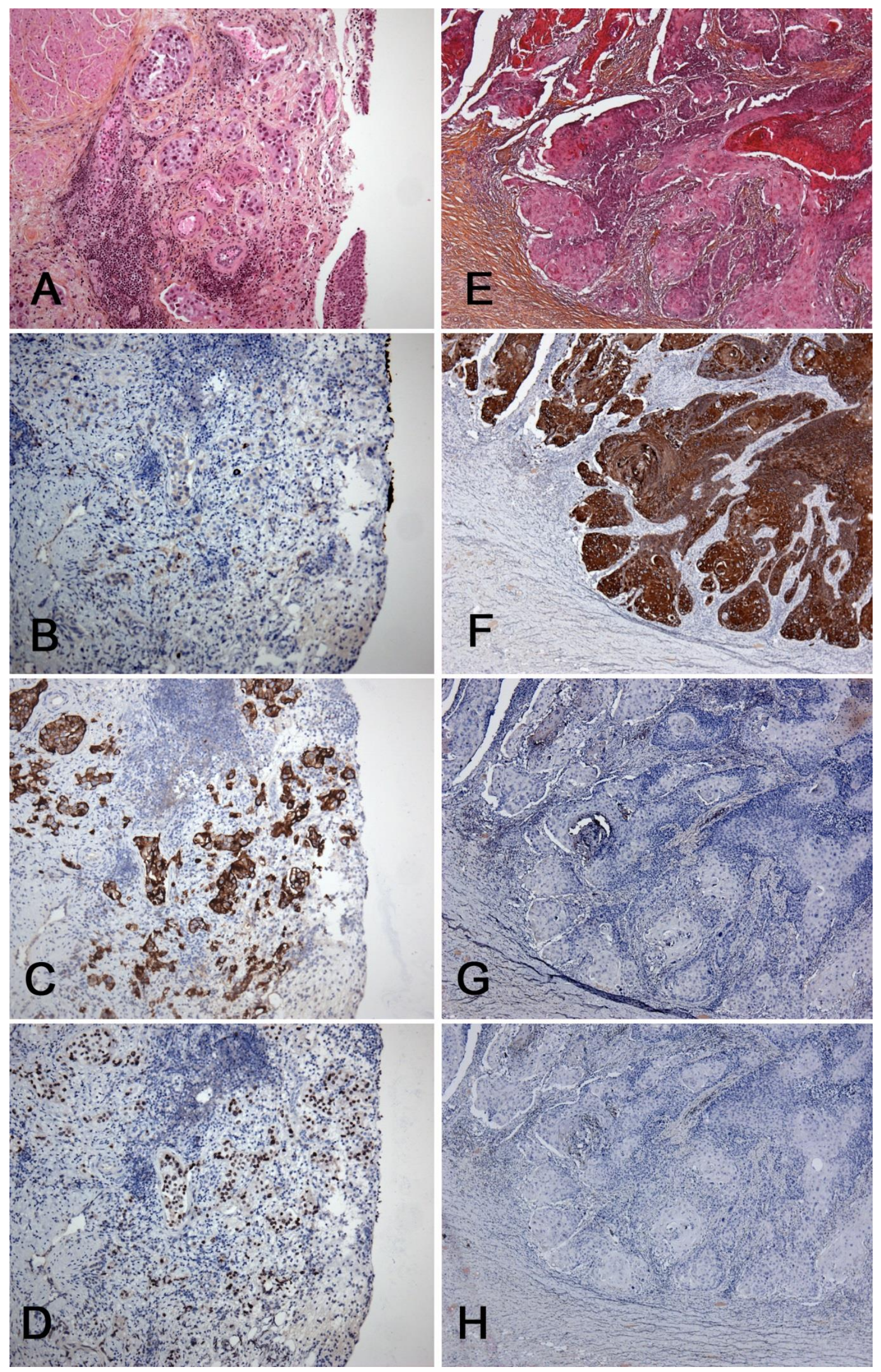

Fig. $5^{\mathrm{L}}$ 